\title{
BMJ Open Associations between shift work characteristics, shift work schedules, sleep and burnout in North American police officers: a cross-sectional study
}

\author{
Scott A Peterson, ${ }^{1}$ Alexander P Wolkow (D) , ${ }^{1,2}$ Steven W Lockley, ${ }^{1,3,4}$ \\ Conor S O'Brien, ${ }^{3}$ Salim Qadri, ${ }^{3}$ Jason P Sullivan, ${ }^{3}$ Charles A Czeisler, ${ }^{3,4}$ \\ Shantha M W Rajaratnam, ${ }^{1,3,4}$ Laura K Barger ${ }^{1,3,4}$
}

To cite: Peterson SA, Wolkow AP, Lockley SW, et al. Associations between shift work characteristics, shift work schedules, sleep and burnout in North American police officers: a cross-sectional study. BMJ Open 2019;9:e030302. doi:10.1136/ bmjopen-2019-030302

- Prepublication history and additional material for this paper are available online. To view please visit the journal (http:// dx.doi.org/10.1136/bmjopen2019-030302).

SAP and APW contributed equally.

Received 07 March 2019 Revised 06 August 2019 Accepted 07 August 2019

Check for updates

(C) Author(s) (or their employer(s)) 2019. Re-use permitted under CC BY-NC. No commercial re-use. See rights and permissions. Published by BMJ.

For numbered affiliations see end of article.

Correspondence to

Dr Laura K Barger;

laura_barger@hms.harvard.edu

\section{ABSTRACT}

Objectives To examine associations between shift work characteristics and schedules on burnout in police and whether sleep duration and sleepiness were associated with burnout.

Methods Police officers $(n=3140)$ completed the Maslach Burnout Inventory (emotional exhaustion, depersonalisation, personal accomplishment) and selfreported shift schedules (irregular, rotating, fixed), shift characteristics (night, duration, frequency, work hours), sleep duration and sleepiness.

Results Irregular schedules, long shifts ( $\geq 11$ hours), mandatory overtime, short sleep and sleepiness were associated with increased risk of overall burnout in police. Police working a greater frequency of long shifts were more likely to have emotional exhaustion (adjusted OR $1.91,95 \% \mathrm{Cl} 1.35$ to 2.72 ) than those not working long shifts. Night shifts were associated with depersonalisation (1.32, 1.05 to 1.66) compared with not working nights. Police working mandatory overtime had increased risk of emotional exhaustion $(1.37,1.14$ to 1.65$)$ than those who did not. Compared with fixed schedules, irregular schedules were associated with emotional exhaustion and depersonalisation (1.91, 1.44 to 2.54 and $1.39,1.02$ to 1.89 , respectively). Police sleeping $<6$ hours were more likely to have emotional exhaustion $(1.60,1.33$ to 1.93$)$ than those sleeping longer, and excessive sleepiness was associated with emotional exhaustion (1.81, 1.50 to 2.18). Conclusions Irregular schedules and increased night shifts, sleep disturbances and work hours were related to higher burnout risk in police. Future research should evaluate work schedules in law enforcement that optimise shift duration and frequency, and increase consistency in scheduling and control over work hours to limit burnout in police.

\section{INTRODUCTION}

A major source of occupational stress for police officers is shift work, which can involve day, night and long duration shifts and long work weeks, ${ }^{12}$ as well as rotating, fixed and irregular shift schedules. ${ }^{3}$ Chronic exposure to occupational stressors can lead to
Strengths and limitations of this study

- The study examined burnout, shift work and sleep in a large sample of police officers $(n=3140)$ from across North America.

- Shift work characteristics and schedules were closely examined in police, providing information on night shifts, long work shifts and long work weeks, overtime (voluntary and mandatory) and different work schedules (irregular, rotating and fixed)

- Sleep and shift information were based on selfreports and thus may be subject to response bias.

- Due to the cross-sectional design of the study, associations between shift work, sleep and burnout can be inferred but not causality.

burnout, which is a psychological syndrome comprising three dimensions: emotional exhaustion (EE), depersonalisation (DP) and a perceived lack of personal accomplishment (PA). ${ }^{4}$ Burnout can have a negative influence on the individual worker, the people whom they serve and their organisation, with consequences including reduced productivity and decision making, ${ }^{5}$ increased absenteeism and risk of leaving the job. ${ }^{6}$ Indeed, retirements due to psychological ill health account for $46 \%$ of medical retirements among police in the UK. ${ }^{7}$ In North American police, sleep disorders have been associated with increased risk of mental health outcomes, including depression and anxiety, and EE and DP burnout dimensions. ${ }^{3}$ In addition to sleep, other work-related factors may also have a negative influence on the health of personnel engaged in shift work; however, few studies have examined how specific characteristics of shift work relate to burnout in police.

Police have traditionally worked 8-10 hour shifts in the USA, although increasingly, departments are implementing compressed 
weekly schedules which involve officers working 11, 12 and 16 hour shifts. ${ }^{138}$ Long shifts are related to increased sleepiness ${ }^{8}$ and may reduce the opportunity for sleep, potentially impairing police officers' ability to recover from work demands. ${ }^{9}$ Short sleep has been found to associate with burnout in shift working occupations, ${ }^{10}$ including law enforcement, ${ }^{11}$ although few studies have examined the relationship between sleepiness and burnout specifically in police. Recovery between shifts may be further restricted by night work, which can cause sleep loss and circadian misalignment and is shown in other healthcare occupations to confer a greater risk of burnout when compared with day shifts. ${ }^{10} \mathrm{~A}$ high degree of burnout has also been associated with working more night shifts among physicians ${ }^{12}$ and longer duration shifts and work weeks in nurses ${ }^{13} 14$ and emergency medical technicians (EMTs). ${ }^{15}$ Although hours of work were not significantly associated with burnout in resident physicians, burnout was related to increased difficulty concentrating on work. ${ }^{16}$ In police, officers who were continuously engaged in shift work were reported to have lower PA, but this study did not describe the relationship between regular shift work and EE or DP nor did it distinguish between the different shift types in policing, ${ }^{17}$ such as night and long duration shifts. Furthermore, police also work a variety of different schedules including irregular, rotating and fixed shifts, ${ }^{9}$ and often do overtime which may be associated with burnout, ${ }^{18}$ but to date, the potential relationship between work schedules and shift characteristics on burnout has not been systematically examined in police.

In this cross-sectional study, we examined whether characteristics of shifts (night, shift duration, frequency, weekly work and overtime hours) as well as shift schedules (irregular, rotating, fixed) were associated with burnout in police. Given that short sleep and sleepiness are also common stressors among police and potential consequences of shift work, ${ }^{3}$ a secondary aim was to investigate associations between sleep duration and sleepiness on burnout risk in police.

\section{METHODS}

\section{Participants}

Volunteers were invited to participate through meetings at police departments and advertisements in police magazines, newsletters and on police-focused websites. In total, 6022 sworn North American police officers expressed interest in the study. Of those, 4957 consented to participate in a survey, either online or, in a few departments, on-site (via pencil/paper). Participant recruitment and survey administration details have been described previously. ${ }^{3}$ The survey assessed demographics and health information, and participants reported work and sleep hours in the past 4 weeks and completed the Maslach Burnout Inventory (MBI). Of the 4957 officers who participated, 3140 completed at least one burnout dimension subscale in the MBI and were eligible for analyses. All participants provided informed consent and were eligible for a prize drawing valued up to US $\$ 1000$.

\section{MEASURES}

Burnout was assessed using the MBI-Human Services Survey, ${ }^{4}$ which consists of 22 items that assess the three burnout dimensions: EE, DP and PA. Participants rated the frequency with which they experienced each item on a 7 -point Likert scale ( $0=$ never; $6=$ =veryday). EE and DP were defined as dichotomous variables, in which a high (vs low-moderate) risk score for these dimensions were determined (high $\mathrm{EE} \geq 27$ points; high $\mathrm{DP} \geq 13$ points). $\mathrm{PA}$ was also a dichotomous variable, but it was scored in the opposite direction to EE and DP, in which low (vs highmoderate) scores indicated low PA ( $\leq 31$ points). Participants were considered to have high overall burnout if they had both high EE and DP, with or without low PA. ${ }^{19}$

Work information was determined using items from both the baseline and a concurrent monthly report. Participants were asked how frequently they worked night shifts (shifts involving $\geq 6$ hours on-duty between 22:00 and 08:00), with responses from 'never or nearly never', '1-4 times per month', ' $1-4$ times per week' and 'nearly every day'. To determine the frequency of long work shifts, participants reported the shift length they worked each week for the previous 4 weeks (ie, 8-10, 11-15, $16-19,20-23$ or $\geq 24$ hours). Based on previous research in human service occupations, ${ }^{14}$ long work shifts were classified as $\geq 11$ hours, from which officers were grouped into those working $0,>0$ to $<2, \geq 2$ to $<4$ and $\geq 4$ long shifts per week.

Participants' usual shift schedules were categorised as 'fixed', 'irregular', 'rotating' or 'other' schedules. Participants reporting that they 'do not have a variable work schedule' were classified as having 'fixed' schedules. Schedules were categorised as 'rotating' if officers reported working shifts that rotated on a day-to-evening, day-to-night or evening-to-night basis. Irregular schedules were defined as shifts that rotated but did not follow a consistent pattern and 'other' comprised schedules that included non-day-to-day rotations (eg, weekly/ monthly rotations). Total work hours across the month were recorded using a validated questionnaire, ${ }^{20}$ with those recording $\geq 48$ hours per week considered to be working long work weeks. This categorisation was based on prior benchmarking literature in the USA which defines long work weeks as 48 or more hours per week ${ }^{21}$ and research which has shown this cut-off to be associated with burnout. ${ }^{22}$ Participants also recorded if they completed mandatory and/or voluntary overtime over the last 4 weeks and the total number of hours they slept each week for the previous 4 weeks. For sleep duration, the combined total of the 4 weeks was used to calculate the average sleep duration per 24 hours, and short sleep was defined as $<6$ hours sleep per 24 hours. Daytime sleepiness was measured using the Epworth Sleepiness Scale 
(ESS; range 0-24), and a score $\geq 11$ indicated excessive sleepiness. $^{23}$

\section{Statistical analysis}

To check for outliers, z-scores were obtained for each variable. Z-scores of \pm 3.29 were considered outliers and were changed using the winsorizing method. This involved changing the score of any value that was deemed an outlier to the nearest non-outlier score in the data set. This was done for age, body mass index (BMI), number of hours worked, and years in law enforcement. Multiple logistic regression models were then used for cross-sectional analysis of associations between shift work (shift work characteristics and schedules), sleep duration, sleepiness and burnout (overall burnout, EE, DP, PA). A multicollinearity assessment using variance inflation factor, correlation coefficient and tolerance values showed no collinearity in the predictor variables (see online supplement file 1, tables $\mathrm{S} 1$ and S2). The models were adjusted for age, BMI, gender, marital status, hypertension, exercise (per week), cigarette smoking (yes/no), caffeine and alcohol consumption (yes/ no during last week), primary police activity (patrol officer, supervisor/manager, detective), years as police officer and seniority. These potentially confounding factors were selected based on prior studies. ${ }^{34-27}$ Each confounder was tested individually with the burnout outcome, and we only included those that were significant $(p<0.10)$ in initial models. ${ }^{28} \mathrm{~A}$ backwards elimination method was then used to remove those that were not significant at the $<0.05$ level when all variables were included in a single model. Factors that remained were used in the first step of a hierarchical logistic regression model. The predictor variables were then added in the second step of the model that included the selected confounding factors. Model fit was assessed using the omnibus test and goodness-of-fit indices (-2 log likelihood). Unadjusted and adjusted OR with $95 \%$ CIs are reported. Our analysis included several multilevel predictors, such as night shift frequency and shift work schedules. For night shift frequency, we hypothesised a priori that a greater frequency of night shifts would be more strongly associated with burnout compared with lower frequencies. Therefore, we compared never/nearly never working night shifts to working night shifts nearly every day and 1-4 times per week to examine if high frequency compared with low frequency of night shifts were associated with worse burnout. Furthermore, we hypothesised a priori that more variable shift work would be related to high burnout, and thus compared fixed shifts to all other categories of shift work (ie, irregular, rotating and other) to examine whether greater variation in schedules predicted higher burnout. Statistical analyses were conducted using SPSS V.24.0 (IBM) and significance set at $\mathrm{p}<0.05$.

\section{Patient and public involvement}

The current study was based on secondary data from a preexisting data set. Therefore, patients and the general public were not involved in the development of the research questions, outcome measures or design of the study.

\section{RESULTS}

Police officers were aged $38.48 \pm 8.31($ mean \pm SD) years and had $12.70 \pm 11.00$ years of experience in law enforcement. Female officers $(16.7 \%)$ in our sample were slightly over-represented compared with police in North America $(12.2 \%) .{ }^{29}$ The sample was predominantly white (table 1$)$, with racial and ethnic minority groups slightly underrepresented compared with national police statistics. ${ }^{29}$ The prevalence of overweight or obesity based on BMI were over-represented in the sample $(80.0 \%)$ (table 1 ) compared with general population data $(70.0 \%){ }^{30}$ Overall burnout was found in $17.7 \%$ of police. High EE and high DP were observed in $23.8 \%$ and $42.6 \%$ of the sample, respectively, and low PA was observed in $40.7 \%$. In the last month, $56.7 \%$ of police worked $\geq 1$ night shift, $63.9 \%$ worked $\geq 1$ long shift, and $33.6 \%$ had an irregular or rotating schedule. Mean total work hours were $192.27 \pm 74.82$ hours/month, mean mandatory overtime was $8.23 \pm 14.01$ hours/month, and mean voluntary overtime was $12.97 \pm 19.76$ hours $/$ month. Short sleep duration was observed in $30.4 \%$ of police, and $25.8 \%$ had excessive sleepiness (table 1).

\section{Shift characteristics and burnout}

The odds of high EE increased in a dose-response manner as a function of the number of long shifts worked per week, with police completing $\geq 4$ long shifts per week having the greatest risk (adjusted OR 1.91, 95\% CI 1.35 to 2.72), compared with no long shifts. A similar relationship was demonstrated for overall burnout, with police working $>0$ to $<2$ and $\geq 4$ long shifts per week more likely to have overall burnout (1.44, 95\% CI 1.02 to 2.02 and $1.78,95 \%$ CI 1.21 to 2.61, respectively) compared with no long shifts (table 2); even one long shift per month increased the risk of burnout (1.4-1.5-fold increase; see online supplementary tables S3, S4 and S5). Working $\geq 48$ hours per week was associated with reduced odds of low PA (0.83, $95 \%$ CI 0.71 to 0.97 ) compared with shorter weeks. Neither long shift frequency nor weekly work hours were related to DP. Compared with police who never/ nearly never work night shifts, those working night shifts nearly every day were at an increased risk of high DP (1.32, 95\% CI 1.05 to 1.66$)$. Working night shifts one to four times per week was associated with lower odds of low PA $(0.79,95 \%$ CI 0.64 to 0.98$)$ compared with never working nights. Police reporting mandatory overtime had an increased risk of overall burnout $(1.40,95 \%$ CI 1.14 to 1.71$)$, high EE (1.37, 95\% CI 1.14 to 1.65$)$ and DP (1.24, 95\% CI 1.04 to 1.47$)$, whereas voluntary overtime was only associated with high DP $(1.19,95 \%$ CI 1.02 to 1.40 ). Reporting any overtime (mandatory or voluntary) was also associated with overall burnout 


\section{Table 1 Participant characteristics}

\section{Characteristic}

N 3140

Age, mean (SD) years

Gender, $\mathrm{n}(\%)$

$\begin{array}{ll}\text { Male } & 2609(83.3) \\ \text { Female } & 523(16.7) \\ \text { Not known } & 8(0.3)\end{array}$

Body mass index, $\mathrm{n}(\%)$

$<25 \mathrm{~kg} / \mathrm{m}^{2} \quad 610(19.4)$

$\geq 25$ and $<30 \mathrm{~kg} / \mathrm{m}^{2} \quad 1460$ (46.5)

$\geq 30$ and $<35 \mathrm{~kg} / \mathrm{m}^{2} \quad 781$ (24.9)

$\geq 35 \mathrm{~kg} / \mathrm{m}^{2} \quad 271(8.6)$

Not known $18(0.6)$

Race, $n$ (\%)

White 2681 (85.4)

Black 257 (8.2)

Asian $34(1.1)$

Native American $21(0.7)$

Pacific Islander $\quad 1(0.03)$

Other 100 (3.2)

Not known 46 (1.5)

Ethnicity, $\mathrm{n}(\%)$

Hispanic $162(5.2)$

Other $2806(89.4)$

Not known $172(5.5)$

Overtime hours per month, mean (SD)

$\begin{array}{ll}\text { Mandatory } & 8.23(14.01) \\ \text { Voluntary } & 12.97(19.76) \\ \text { Total } & 19.46(23.18)\end{array}$

Night shift frequency, $\mathrm{n}(\%)$

Never or nearly never $1290(41.1)$

1-4 per week $612(19.5)$

1-4 per month $\quad 584$ (18.6)

Nearly every day $615(19.6)$

Not known 39 (1.2)

\begin{tabular}{|c|c|}
\hline \multicolumn{2}{|c|}{$\begin{array}{l}\text { Long work shifts per week ( } \geq 11 \text { hours), } \\
n(\%)\end{array}$} \\
\hline None & 390 (12.4) \\
\hline$>0-<2$ & $1029(32.8)$ \\
\hline$\geq 2-<4$ & $496(15.8)$ \\
\hline$\geq 4$ & $482(15.4)$ \\
\hline Not known & $743(23.7)$ \\
\hline \multicolumn{2}{|c|}{ Work hours per week, n (\%) } \\
\hline$<48$ hours & $1820(58.0)$ \\
\hline$\geq 48$ hours & $1260(40.1)$ \\
\hline Not known & $60(1.9)$ \\
\hline Usual shift sch & \\
\hline
\end{tabular}

Continued
Table 1 Continued

\begin{tabular}{|c|c|}
\hline Characteristic & Data \\
\hline Fixed & $1822(58.0)$ \\
\hline Irregular & $274(8.7)$ \\
\hline Rotating & $782(24.9)$ \\
\hline Other & 239 (7.6) \\
\hline Not known & $23(0.7)$ \\
\hline \multicolumn{2}{|c|}{$\begin{array}{l}\text { Average sleep duration over the last } 4 \\
\text { weeks }^{\star}, n(\%)\end{array}$} \\
\hline$<6$ hours & $956(30.4)$ \\
\hline$\geq 6$ hours & $1780(56.7)$ \\
\hline Not known & $404(12.9)$ \\
\hline \multicolumn{2}{|l|}{ Daytime sleepiness, n (\%) } \\
\hline Normal (<11 ESS) daytime sle & $2195(69.9)$ \\
\hline $\begin{array}{l}\text { Excessive ( } \geq 11 \text { ESS) daytime } \\
\text { sleepiness }\end{array}$ & $809(25.8)$ \\
\hline Not known & $136(4.3)$ \\
\hline \multicolumn{2}{|l|}{ Burnout, $\mathrm{n} \dagger(\%)$} \\
\hline High EE & $747(23.8)$ \\
\hline High DP & $1338(42.6)$ \\
\hline Low PA & $1278(40.7)$ \\
\hline Overall burnoutł & $556(17.7)$ \\
\hline
\end{tabular}

Police officers that had at least 1

dimension of burnout, $\mathrm{n}(\%)$

$\begin{array}{ll}\text { No } & 1072(34.1) \\ \text { Yes } & 2068(65.9)\end{array}$

*Per 24-hour period.

†The burnout characteristics are not mutually exclusive (eg, a participant could have both high EE and low PA).

‡Defined as high EE, high DP, with or without low PA.

DP, depersonalisation; EE, emotional exhaustion; ESS, Epworth

Sleepiness Scale; PA, personal accomplishment.

(1.37, 95\% CI 1.06 to 1.75$)$ and high DP (1.45, 95\% CI 1.20 to 1.76 ). Overtime was not related to PA.

\section{Work schedules and burnout}

Police working irregular schedules were at greatest risk of overall burnout (2.12, 95\% CI 1.57 to 2.85), followed by high EE (1.91, 95\% CI 1.44 to 2.54) and high DP (1.39, 95\% CI 1.02 to 1.89$)$ compared with those working fixed schedules. Compared with fixed schedules, police reporting rotating and 'other' schedules were more likely to have EE $(1.30,95 \%$ CI 1.06 to 1.59 and $1.44,95 \%$ CI 1.05 to 1.98 , respectively), but these associations were weaker than those observed for irregular shifts. Furthermore, police working rotating schedules were more likely to have low PA $(1.38,95 \%$ CI 1.15 to 1.64$)$ compared with fixed shifts. Rotating or 'other' schedules were not associated with overall burnout or DP, and irregular or 'other' shift schedules were not related to PA (table 3). 


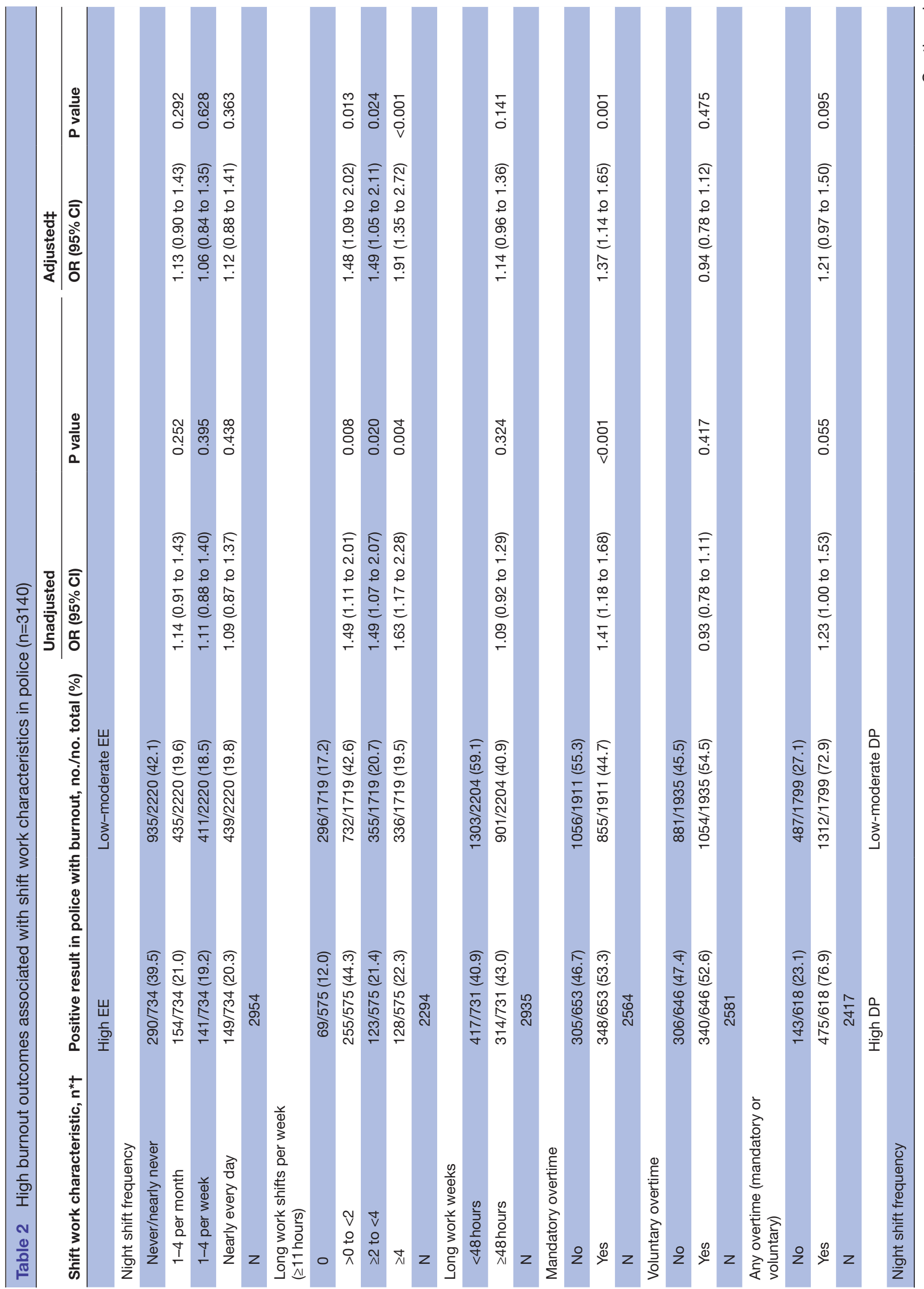

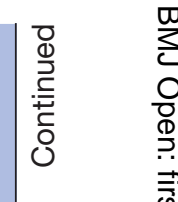




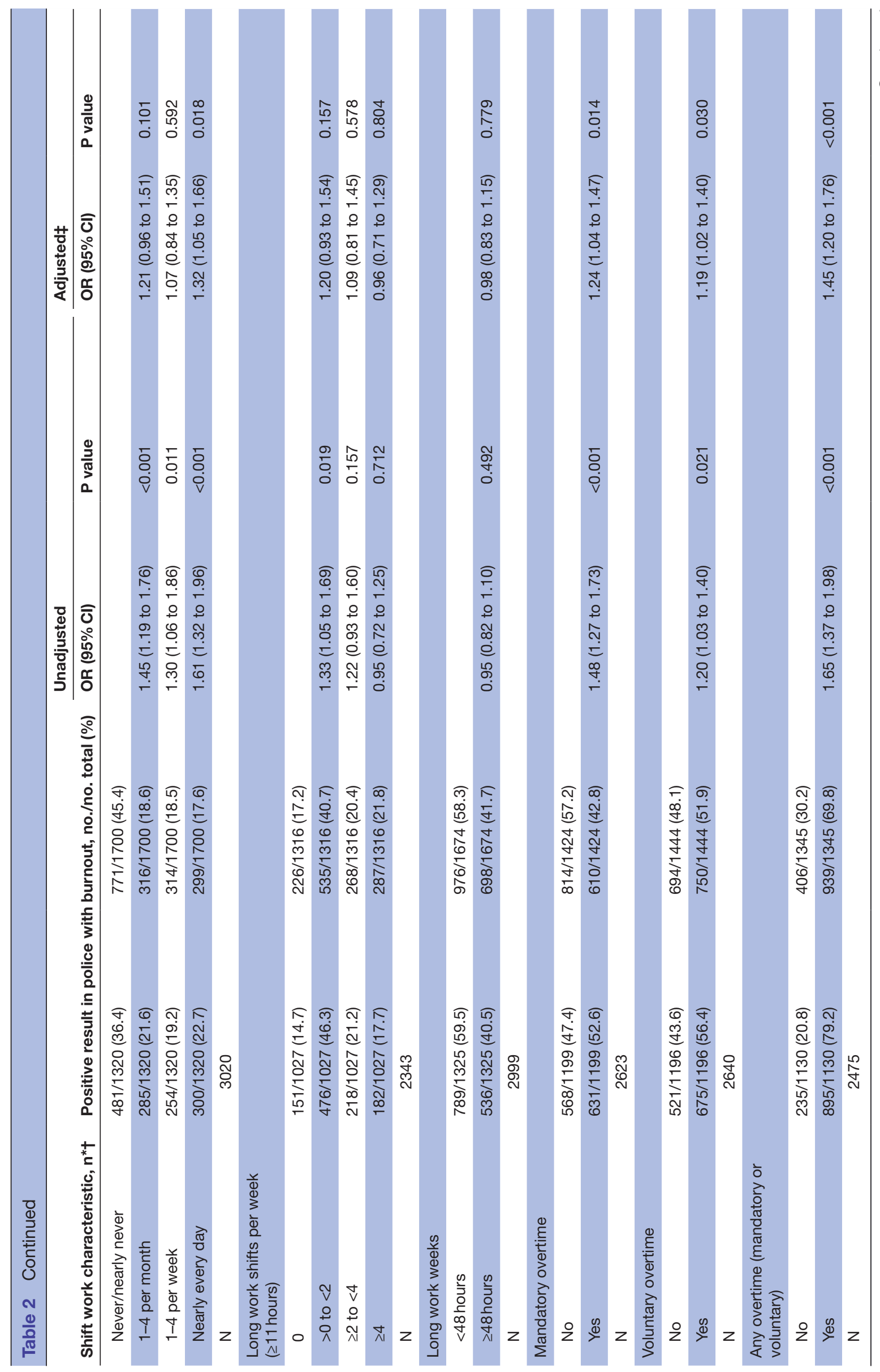




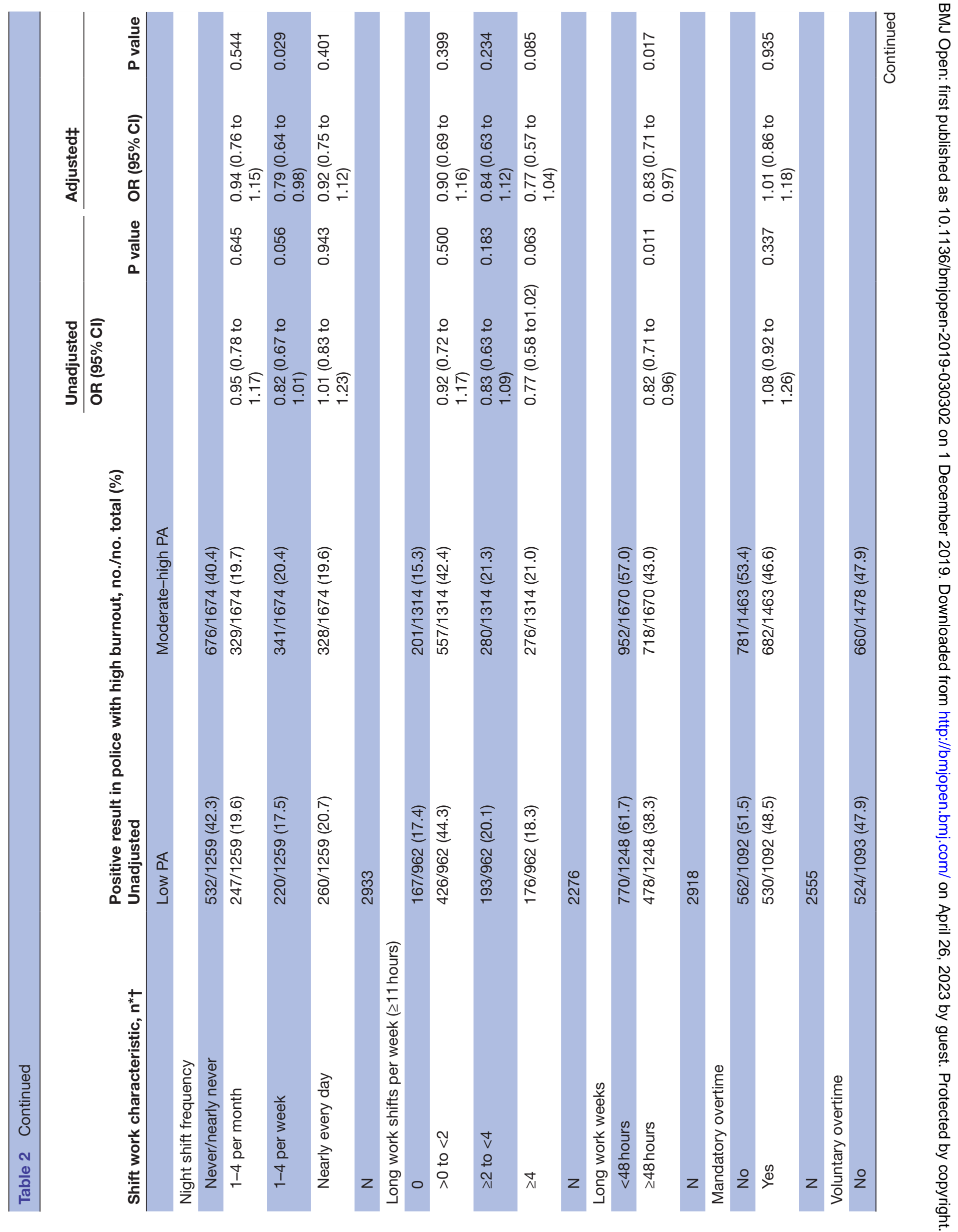




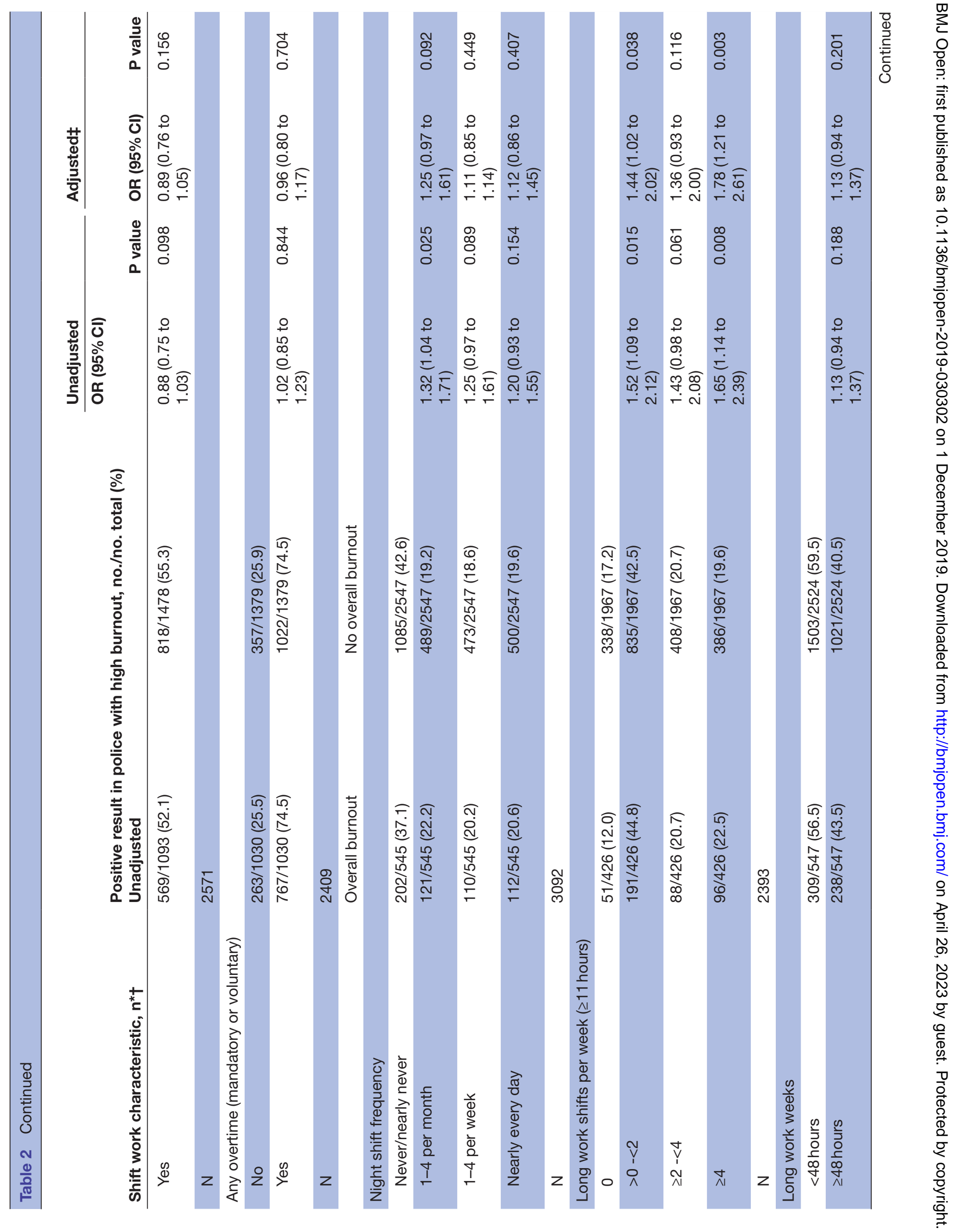




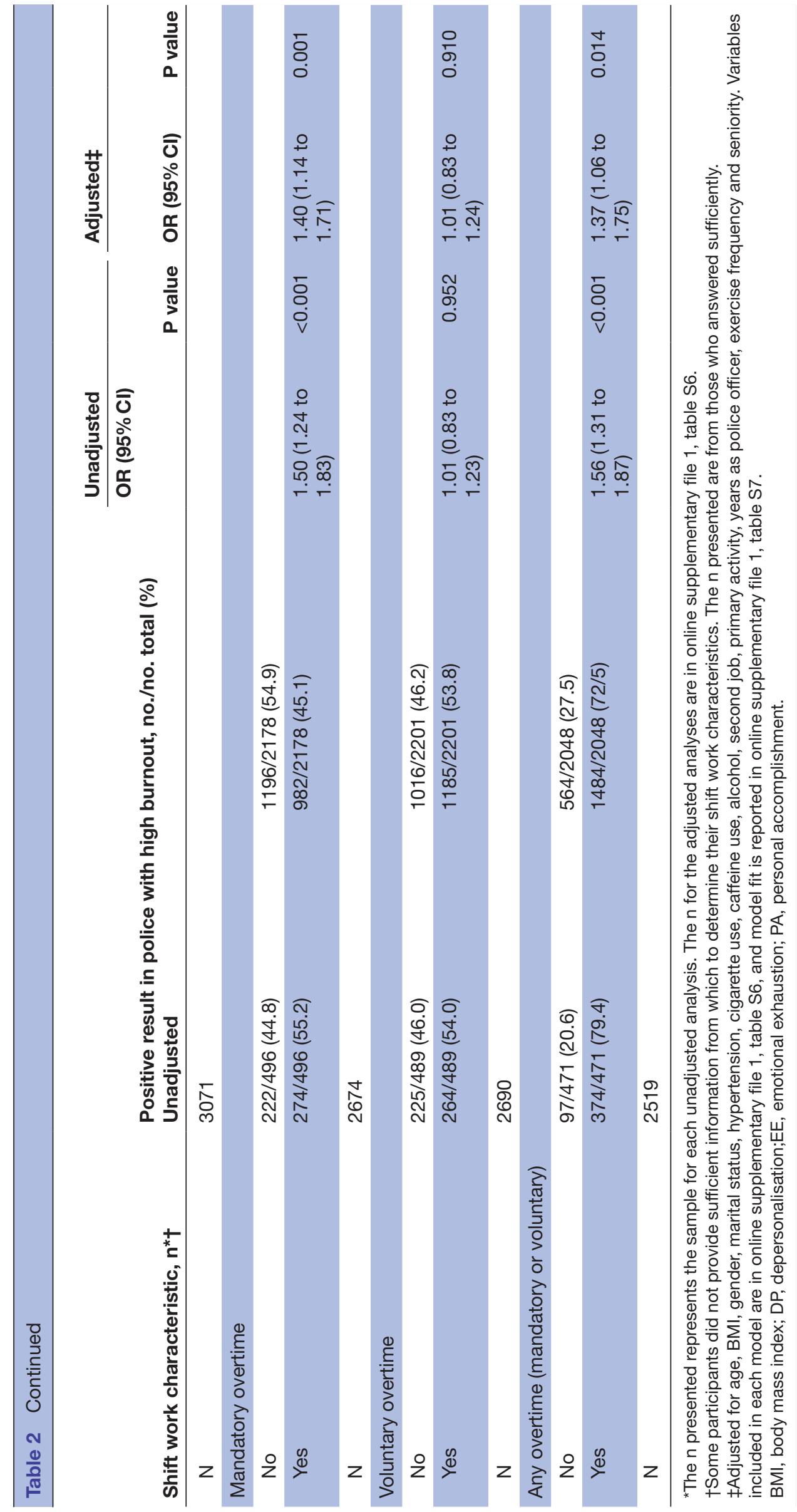


Table 3 High burnout outcomes associated with shift work schedules in police $(n=3140)$

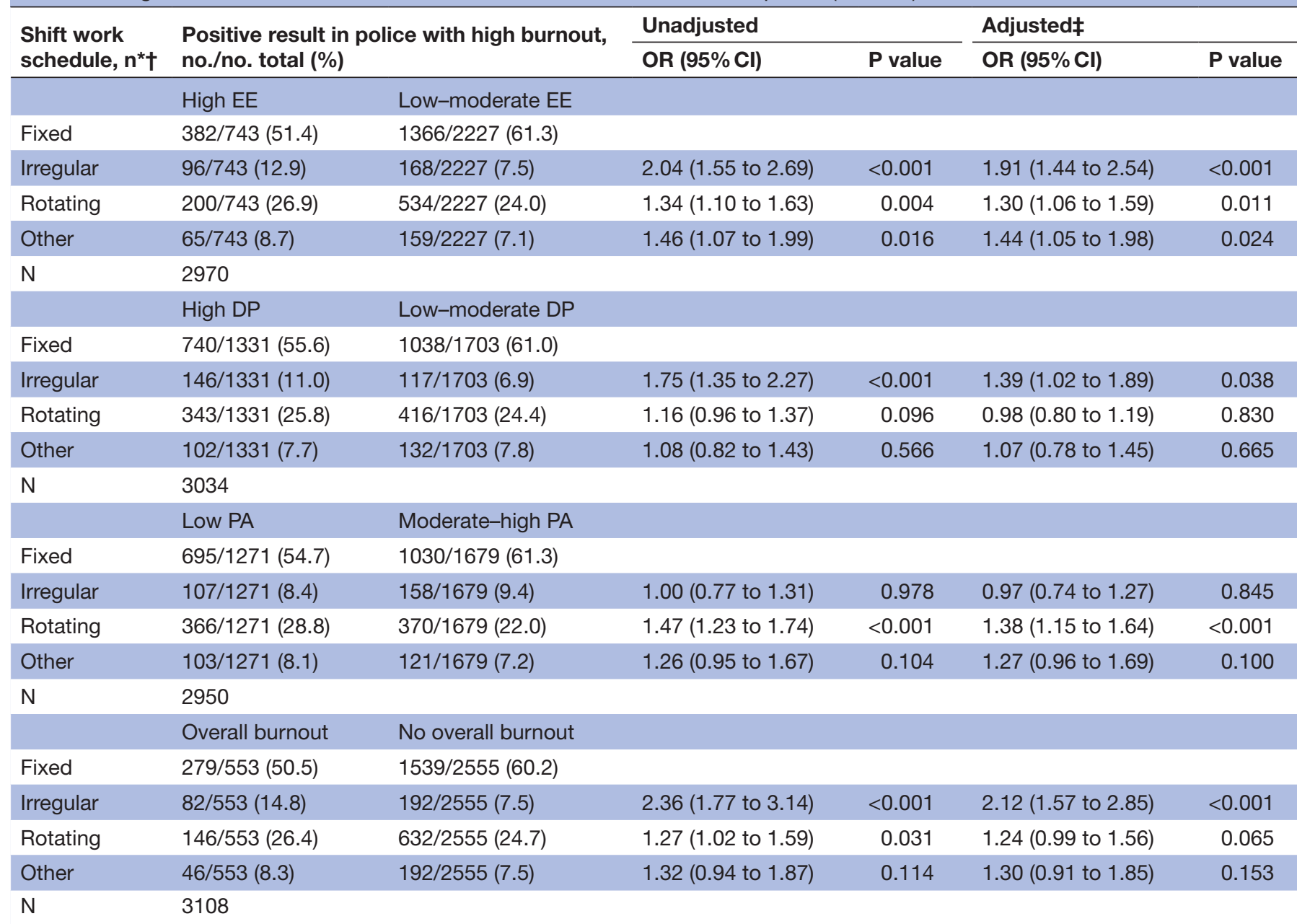

*The $\mathrm{n}$ represents the sample for each unadjusted analysis. The $\mathrm{n}$ for the adjusted analyses are in online supplementary file 1 , table S6. †Some participants did not provide sufficient information from which to determine their shift work characteristics. The $\mathrm{n}$ presented are from those who answered sufficiently.

ҒAdjusted for age, BMI, gender, marital status, hypertension, cigarette use, caffeine use, alcohol, second job, primary activity, years as police officer, exercise frequency and seniority. Variables included in each model are in online supplementary file 1, table S6, and model fit is reported in online supplementary file 1, table S7.

BMI, body mass index; DP, depersonalisation; EE, emotional exhaustion; PA, personal accomplishment.

\section{Sleep and burnout}

Police who reported, on average, short sleep ( $<6$ hours) were more likely to have overall burnout $(1.49,95 \% \mathrm{CI}$ 1.21 to 1.82$)$, high $\mathrm{EE}(1.60,95 \% \mathrm{CI} 1.33$ to 1.93$)$ and low PA (1.24, 95\% CI 1.05 to 1.47$)$ compared with those sleeping $\geq 6$ hours. Short sleep was not associated with DP (table 4). Police with excessive sleepiness were more likely to have overall burnout $(1.72,95 \%$ CI 1.41 to 2.11$)$, high EE (1.81, 95\% CI 1.50 to 2.18) and high DP (1.48, $95 \%$ CI 1.23 to 1.78 ) compared with police with normal sleepiness (table 4).

\section{DISCUSSION}

In this sample of North American police officers, 17\% exhibited overall burnout, which is higher than the $10 \%$ previously observed in office workers. ${ }^{19}$ Almost two-thirds of the sample $(65.9 \%)$ were also found to have at least one dimension of burnout, and this too exceeds levels reported in other human service occupations and the general population. ${ }^{31}$ Long shifts, mandatory overtime, short sleep and sleepiness were each associated with significantly increased risk of overall burnout in police. Among the different schedules, officers working irregular shifts had a twofold higher risk of overall burnout, demonstrating the risk of burnout associated with this schedule for the first time in police. For individual dimensions of burnout, almost half of police had high depersonalisation $(42.6 \%)$, the same was true for low personal accomplishment $(40.7 \%)$, while nearly a quarter had high emotional exhaustion $(23.8 \%)$. The prevalence of DP was higher in this sample of police compared with the US general population (15\%), and EE levels were similar to general population data $(23 \%) .{ }^{31}$ The risk of EE was higher in police working a greater frequency of long shifts, and 
Table 4 High burnout outcomes associated with sleep duration and sleepiness in police $(n=3140)$

\begin{tabular}{|c|c|c|c|c|c|c|}
\hline \multirow[b]{2}{*}{ Sleep characteristics, $n^{\star} \dagger$} & \multirow{2}{*}{\multicolumn{2}{|c|}{$\begin{array}{l}\text { Positive result in police with high burnout, } \\
\text { no./no. total (\%) }\end{array}$}} & \multicolumn{2}{|l|}{ Unadjusted } & \multicolumn{2}{|l|}{ Adjusted $\ddagger$} \\
\hline & & & \multirow[t]{2}{*}{ OR $(95 \% \mathrm{Cl})$} & \multirow[t]{2}{*}{$P$ value } & \multirow[t]{2}{*}{ OR $(95 \% \mathrm{Cl})$} & \multirow[t]{2}{*}{$P$ value } \\
\hline & High EE & Low-moderate EE & & & & \\
\hline \multicolumn{7}{|l|}{ Sleep duration } \\
\hline$\geq 6$ hours per night & $371 / 654(56.7)$ & 1334/1956 (68.2) & & & & \\
\hline$<6$ hours per night & 283/654 (43.3) & 622/1956 (31.8) & $1.64(1.36$ to 1.96$)$ & $<0.001$ & $\begin{array}{l}1.60(1.33 \text { to } \\
1.93)\end{array}$ & $<0.001$ \\
\hline$N$ & 2610 & & & & & \\
\hline \multicolumn{7}{|l|}{ Sleepiness } \\
\hline$<11$ ESS & $451 / 714(63.2)$ & $1652 / 2158$ (76.6) & & & & \\
\hline$\geq 11$ ESS & 263/714 (36.8) & $506 / 2158(23.4)$ & $1.90(1.59$ to 2.28$)$ & $<0.001$ & $\begin{array}{l}1.81(1.50 \text { to } \\
2.18)\end{array}$ & $<0.001$ \\
\hline \multirow[t]{2}{*}{$\mathrm{N}$} & 2872 & & & & & \\
\hline & High DP & Low-moderate DP & & & & \\
\hline \multicolumn{7}{|l|}{ Sleep duration } \\
\hline$\geq 6$ hours per night & $755 / 1206(62.6)$ & $989 / 1469$ (67.3) & & & & \\
\hline$<6$ hours per night & $451 / 1206(37.4)$ & $480 / 1469$ (32.7) & $1.23(1.05$ to 1.44$)$ & 0.011 & $\begin{array}{l}1.13(0.96 \text { to } \\
1.33)\end{array}$ & 0.151 \\
\hline $\mathrm{N}$ & 2675 & & & & & \\
\hline \multicolumn{7}{|l|}{ Sleepiness } \\
\hline$<11$ ESS & $875 / 1286(68.0)$ & $1267 / 1639$ (77.3) & & & & \\
\hline$\geq 11$ ESS & $411 / 1286$ (32.0) & $372 / 1639$ (22.7) & $1.60(1.38$ to 1.89$)$ & $<0.001$ & $\begin{array}{l}1.48(1.23 \text { to } \\
1.78)\end{array}$ & $<0.001$ \\
\hline \multirow[t]{2}{*}{$\mathrm{N}$} & 2925 & & & & & \\
\hline & Low PA & Moderate-high PA & & & & \\
\hline \multicolumn{7}{|l|}{ Sleep duration } \\
\hline$\geq 6$ hours per night & 670/1077 (62.2) & $1024 / 1524$ (67.2) & & & & \\
\hline$<6$ hours per night & 407/1077 (37.8) & $500 / 1524$ (32.8) & $1.24(1.06$ to 1.46$)$ & 0.009 & $\begin{array}{l}1.24(1.05 \text { to } \\
1.47)\end{array}$ & 0.011 \\
\hline $\mathrm{N}$ & 2601 & & & & & \\
\hline \multicolumn{7}{|l|}{ Sleepiness } \\
\hline$<11$ ESS & $867 / 1224$ (70.8) & $1213 / 1627$ (74.6) & & & & \\
\hline$\geq 11$ ESS & $357 / 1224$ (29.2) & $414 / 1627$ (25.4) & $1.21(1.02$ to 1.43$)$ & 0.027 & $\begin{array}{l}1.18(0.99 \text { to } \\
1.41)\end{array}$ & 0.061 \\
\hline \multirow[t]{2}{*}{$N$} & 2851 & & & & & \\
\hline & Overall burnout & No overall burnout & & & & \\
\hline \multicolumn{7}{|l|}{ Sleep duration } \\
\hline$\geq 6$ hours per night & 279/491 (56.8) & $1497 / 2238$ (66.9) & & & & \\
\hline$<6$ hours per night & $212 / 491$ (43.2) & $741 / 2238$ (33.1) & $1.54(1.26$ to 1.87$)$ & $<0.001$ & $\begin{array}{l}1.49(1.21 \text { to } \\
1.82)\end{array}$ & $<0.001$ \\
\hline $\mathrm{N}$ & 2729 & & & & & \\
\hline \multicolumn{7}{|l|}{ Sleepiness } \\
\hline$<11$ ESS & $338 / 532$ (63.5) & $1852 / 2464$ (75.2) & & & & \\
\hline$\geq 11$ ESS & 194/532 (36.5) & $612 / 2464(24.8)$ & $1.74(1.42$ to 2.12$)$ & $<0.001$ & $\begin{array}{l}1.72(1.41 \text { to } \\
2.11)\end{array}$ & $<0.001$ \\
\hline $\mathrm{N}$ & 2996 & & & & & \\
\hline
\end{tabular}

*The $\mathrm{n}$ presented represents the sample for each unadjusted analysis. The $\mathrm{n}$ for the adjusted analyses are in online supplementary file 1 , table S6. †Some participants did not provide sufficient information from which to determine their sleep duration and sleepiness. The $\mathrm{n}$ presented are from those who answered sufficiently.

$\ddagger$ Adjusted for age, BMI, gender, marital status, hypertension, cigarette use, caffeine use, alcohol use, second job, primary activity, years as police officer, exercise frequency and seniority. Variables included in each model are in online supplementary file 1, table S6, and model fit is reported in online supplementary file 1 , table $\mathrm{S} 7$.

BMI, body mass index; DP, depersonalisation; EE, emotional exhaustion; ESS, Epworth Sleepiness Scale; PA, personal accomplishment. 
working night shifts nearly every day were associated with an increased risk of DP. Long work weeks were associated with reduced odds of low PA, and mandatory, but not voluntary, overtime increased EE. There was an increased likelihood of EE and PA among police reporting short sleep and an increased risk for EE and DP in those with excessive sleepiness.

Police regularly completing long work shifts were at increased risk of overall burnout and high EE. Previous studies in nurses have reported similar associations between increased hours of work on the most recent shift and high burnout. ${ }^{13}{ }^{14}$ We expand on these findings by demonstrating how the risk of EE is dependent on the number of long shifts worked, with working $\geq 4$ long shifts associated with nearly double the risk of EE. Working $\geq 1$ long shift per month and $\geq 4$ long shifts per week were also associated with high $\mathrm{EE}$ and overall burnout, but the risk conferred by other shift frequencies (ie, $>0$ to $<2,2$ to $<4$ long shifts per week) was less consistent for these aspects of burnout. Working $\geq 48$ hours per week was associated with reduced odds of low PA in police, which contrasts research in physicians using a similar definition of weekly work hours, ${ }^{22}$ as well as a prior study in UK police that defined long work weeks using a slightly higher threshold ( $\geq 49$ hours per week) ${ }^{27}$ Long work weeks and night shifts (1-4 per week) were the only shift characteristics in this study associated with reduced odds of low PA. Although these findings were unexpected, they may highlight certain aspects of shift work in policing that allow personnel to feel effective and a sense of accomplishment in their work, but further research that explores the relationships between PA and weekly night shifts (eg, comparing 1-2 and 3-4 night shifts per week) and work hours (eg, $\geq 49$ or $\geq 60$ hours) in more detail is needed to confirm these findings. Compared with weekly work hours, however, the associations between long work shifts and burnout were positive, typically stronger and affected more burnout dimensions. This is an important detail, as it demonstrates how the distribution of work hours, not just total overall hours, influences burnout in police. This suggests the need for shorter and less compressed shifts that spread work hours across the week to reduce burnout. For instance, Amendola $e t a l^{8}$ found that police working 10 hour shifts reported longer sleep and higher quality of work-life balance compared 8 or 12 hour shifts, although burnout was not examined in that study. Further research is needed to examine whether shortening shift lengths, as well as limiting the frequency of long work shifts, also reduces burnout in police as it has been shown in EMTs. ${ }^{15}$

Mandatory overtime was associated with an increased risk of overall burnout, high EE and DP among police. Conversely, voluntary overtime was not associated with EE or overall burnout but was associated with high DP. A prior study in police failed to show a relationship between overtime (combined voluntary and mandatory) and burnout. ${ }^{18}$ The results of our study suggest the control a police officer has over overtime may influence how closely this shift characteristic is associated with burnout, in particular overall burnout and EE. This interpretation is supported by research from Beckers $e t$ $a l^{32}$ in full-time workers who reported involuntary overtime was associated with high emotional fatigue and low job satisfaction, and classified involuntary overtime workers as a burnout risk group. In their study, Beckers and colleagues ${ }^{32}$ did not examine DP, but based on our findings in police, it is possible that voluntary (and mandatory) overtime may pose a risk to this dimension. Further research determining the specific durations of overtime associated with high burnout and which dimensions of burnout is needed to inform policies regarding the safe provision of work hours in excess of normal shift lengths.

Increased frequency of night shifts was associated with high DP in police, but not overall burnout or EE. Research has reported associations between increased night work and burnout in healthcare personnel, but only for overall burnout and EE. ${ }^{12}{ }^{33}$ Furthermore, the rate of night shifts per month was not found to associate with burnout among healthcare workers. ${ }^{33}$ These inconsistencies may reflect differences among human service professions and perhaps their physical environments (eg, lighting levels that affect mood and alertness) ${ }^{34}$ that may impact the manifestation of burnout dimensions. For instance, healthcare workers typically develop higher rates of $\mathrm{EE},{ }^{35}$ whereas police report greater $\mathrm{DP},{ }^{36}$ as demonstrated in the current study. High DP reflects a critical relationship between people and their work, as it refers to negative feelings and attitudes towards one's clients. ${ }^{4}$ Therefore, high DP in police could be due to the difficult nature of some of the people with whom police interact. In addition to sleep disruption with night work, police encounter more stressful events at night. ${ }^{37}$ Sleep is further disrupted among people with untreated sleep disorders, and common sleep disorders are shown to increase the likelihood of police demonstrating anger towards suspects or citizens. ${ }^{3}$ Thus, the combination of poor mood, sleep and difficult clients may explain the increased risk of DP associated with regular night work in police. Further research comparing police attitudes towards clients with whom they interact at night compared with the day is needed to understand the mechanisms underpinning the increased risk of DP conferred by night shifts in police.

Police officers who reported short sleep had a greater risk of overall burnout, high EE and low PA, while sleepiness increased the likelihood for EE, DP and overall burnout. Similar sleepiness levels have been related to high burnout in medical students. ${ }^{26}$ Our findings for sleep duration are also consistent with research showing short sleep over a month increases overall burnout in police. ${ }^{11}$ Inadequate sleep may impair police officers' ability to recover from occupational demands, potentially explaining the heightened burnout risk in those reporting short sleep in this study. Achieving sufficient sleep can be difficult when working at night and/or long hours, as these shifts may limit sleep opportunities at 
night and involve attempts by the shift worker to sleep at times of the day when alertness levels are high (and sleep propensity is low) ${ }^{38}$ Indeed, when restricting the sample to police regularly completing long shifts, officers reporting short sleep and excessive sleepiness had a twofold increased risk of EE (online supplementary tables S8, S4 and S5). These findings highlight the health burden of sleepiness and sleep loss in law enforcement and the need for interventions that address sleep in addition to optimising shift schedules.

Police working irregular shifts were more likely to have overall burnout, high EE and DP compared with officers working fixed shifts. Canadian workers completing non-standard schedules (shifts other than fixed 09:00-17:00) have also been found to have increased overall burnout and EE, ${ }^{39}$ but to our knowledge, this is the only other study to have investigated the relationship between irregular or non-standard schedules and burnout. A growing body of research suggests that greater variability in sleep duration and bedtimes predict worse mental health. ${ }^{40}$ Workers with irregular shifts are likely to have more variability in their sleep patterns, ${ }^{41}$ which in turn, may explain the increased burnout risk among police engaged in this schedule. Considering $8.7 \%$ of our sample worked irregular shifts, our findings may have implications for arranging work schedules to limit irregular shifts to reduce burnout. Rotating shifts were also common among police in our study $(24.9 \%)$ and associated with high EE and low PA. Conversely, nurses working fixed shifts compared with rotating schedules are reported to have greater $\mathrm{EE}$ and $\mathrm{DP},{ }^{42}$ but not low PA, with those working fixed night and morning shifts showing the highest levels of EE and DP. ${ }^{43}$ The hazards related to fixed night shifts are well documented, ${ }^{44}$ although in the current study it was not possible to specifically identify the types of fixed shifts police completed (eg, fixed night vs fixed day shifts). Despite this limitation, when we restricted the analysis to police only working fixed shifts, those reporting a greater frequency of night shifts had an increased risk of DP (see online supplementary tables S9, S10 and S11), which aligns with previous findings for fixed night work. ${ }^{43}$ In addition to the different types of fixed shifts, there is also a diverse range of shift rotations in policing, which were grouped into one variable (ie, rotating schedules) in our study. Specific shift rotations and types of fixed shifts may have varying effects on burnout, thus underspecifying these schedules in the current study may limit the interpretation of our findings. Further research that uses detailed objective shift work information will allow for a more nuanced approach when it comes to examining interactions between different shift schedules and burnout in police and other emergency services.

In addition to subjective shift information, a further limitation of this study was the use of self-reported sleep characteristics. Although some questions used to record police officers' work and sleep hours have been validated, ${ }^{20}$ participants were required to report and recall this information for the prior month. An additional limitation was the cross-sectional design. Future longitudinal studies using objective work and sleep measures are needed to examine the causality within our findings.

The results of this study among police contribute to a growing evidence base in shift workers that indicates how the number of long shifts and night shifts, mandatory overtime and short sleep and sleepiness raise the risk of burnout. Importantly, we further demonstrate that irregular schedules present a significant risk for burnout. These findings support future research in police that trials reducing the rate of long shifts and night shifts per week in vulnerable officers and preventing irregular schedules where possible. Although shift work is unavoidable for industries such as law enforcement, optimising work hours in relation to control over overtime, consistency of schedules and reducing duration and frequency of night and long shifts should be explored as a way to lower the high level of burnout among police, leading to improved health for personnel and enhanced performance for their department and communities whom they serve.

\section{Author affiliations}

${ }^{1}$ Turner Institute for Brain and Mental Health, School of Psychological Sciences, Monash University, Clayton, Victoria, Australia

${ }^{2}$ Paramedic Health and Wellbeing Research Unit, Monash University, Frankston, Victoria, Australia

${ }^{3}$ Division of Sleep and Circadian Disorders, Departments of Medicine and Neurology, Brigham and Women's Hospital, Boston, MA, USA

${ }^{4}$ Division of Sleep Medicine, Harvard Medical School, Boston, MA, USA

Contributors SAP, APW, LKB, CO, JPS, SQ, SWL, CAC and SMWR contributed to the design of the study. LKB, CO, JPS, SQ, SWL, CAC and SMWR contributed to data collection. SAP, APW, LKB and SMWR conducted the data analysis. All authors contributed to the interpretation of the data, and the preparation and refinement of the final manuscript.

Funding This work was supported by grant 2004-FS-BX-0001 and grant 2010C10002 from the National Institute of Justice, Office of Justice Programs, US Department of Justice, grants R01 OH008496 and R01 OH009403 from the Centers for Disease Control and Prevention and grants from the ResMed Foundation. LKB, CAC, SWL, CO and SQ were supported in part by R010H010300.

Disclaimer The funders had no role in the design and conduct of the study; collection, management, analysis and interpretation of the data; preparation, review or approval of the manuscript and decision to submit the manuscript for publication.

Competing interests SAP, APW, JPS, SQ and CO report no conflicts of interest. SMWR reports that he has served as a consultant through his institution to Philips Respironics, EdanSafe, National Transport Commission, Vanda Pharmaceuticals, Rail, Bus and Train Union, Tontine Group, Australian Workers' Union, Transport Accident Commission, Meda Consumer Healthcare, New South Wales Department of Education and Communities, and has through his institution received grants from Philips Respironics and Vanda Pharmaceuticals and reimbursements for conference travel expenses from Vanda Pharmaceuticals. SMWR currently serves as a consult to and is a programme leader for the Cooperative Research Centre for Alertness, Safety and Productivity. SMWR institution has received equipment donations or other support from Compumedics, Philips Lighting, Optalert and Tyco Healthcare. SMWR is a former president of the Australasian Sleep Association and is Director of the Sleep Health Foundation. SMWR has also served as an expert witness and/or consultant to shift work organisations. LKB reports research support from Cephalon, NFL charities, Sysco and San Francisco Bar Pilots. LKB has received consulting/ lecture fees or served as a board member for Alertness Solution, Ceridian, Davis Joint Unified School Board, San Jose State University Foundation, Pugot Sound Pilots, Sygma and Torvec. SWL has no conflicts of interests directly related to the research or results reported in this paper. SWL holds a process patent for 'Systems 
and methods for determining and/or controlling sleep quality', which is assigned to the Brigham and Women's Hospital per Hospital policy. SWL has received consulting fees from the BHP Billiton, EyeJust Inc., Noble Insights, and Team C Racing; honoraria and/or paid travel from BHP Billiton, DIN, Emory University, IES, Ineos, MIT, Roxbury Latin School, SLTBR, Solemma and Teague; has current consulting contracts with Akili Interactive; Apex 2100 Ltd.; Consumer Sleep Solutions; Headwaters Inc.; Hintsa Performance AG; Light Cognitive; Lighting Science Group Corporation; Mental Workout; PlanLED; Six Senses; Stantec; and Wyle Integrated Science and Engineering; has received unrestricted equipment gifts from Bionetics Corporation and F. Lux Software LLC; royalties from Oxford University Press. SWL has served as a paid expert for legal proceedings related to light, sleep and health. SWL is a programme leader for the CRC for Alertness, Safety and Productivity, Australia. CAC reports grants from Cephalon Inc., Jazz Pharmaceuticals PIc. Inc., National Football League Charities, Optum, Philips Respironics Inc., Regeneron Pharmaceuticals, ResMed Foundation, San Francisco Bar Pilots, Sanofi S.A., Sanofi-Aventis Inc., Schneider Inc., Sepracor Inc., Mary Ann \& Stanley Snider via Combined Jewish Philanthropies, Sysco Corp., Takeda Pharmaceuticals Co. Ltd., Teva Pharmaceuticals Industries Ltd., and Wake Up Narcolepsy; and consulting fees from Bose Corporation, Boston Red Sox, Columbia River Bar Pilots, Samsung Electronics, Quest Diagnostics Inc., Teva Pharma Australia, Vanda Pharmaceuticals Inc., Washington State Board of Pilotage Commissioners, and Physician's Seal; lecture fees from Ganésco Inc., Zurich Insurance Company Ltd., American Academy of Dental Sleep Medicine, Eisenhower Medical Center, M. Davis and Company, UC San Diego, and University of Washington; and fees for serving as a member of an advisory board for Institute of Digital Media and Child Development, the Klarman Family Foundation, and the AARP. In addition, CAC holds a number of process patents in the field of sleep/circadian rhythms (e.g., photic resetting of the human circadian pacemaker), and holds an equity interest in Vanda Pharmaceuticals Inc. CAC is the incumbent of an endowed professorship provided to Harvard University by Cephalon Inc. Since 1985, CAC has also served as an expert on various legal and technical cases related to sleep and/or circadian rhythms including those involving the following commercial entities: Casper Sleep Inc., Comair/Delta Airlines, Complete General Construction Company, FedEx, Greyhound, HG Energy LLC, Purdue Pharma, LP, South Carolina Central Railroad Co., Steel Warehouse Inc., StricLan Companies LLC, Texas Premier Resource LLC and United Parcel Service (UPS). CAC received royalties from the New England Journal of Medicine; McGraw Hill; Houghton Mifflin Harcourt/Penguin; and Philips Respironics Inc. for the Actiwatch-2 and Actiwatch-Spectrum devices. CAC interests were reviewed and managed by Brigham and Women's Hospital and Partners HealthCare in accordance with their conflict of interest policies.

Patient consent for publication Not required.

Ethics approval This study was approved by the Ethics Committees of Partners HealthCare (2015P001357/BHW) and Monash University (2736).

Provenance and peer review Not commissioned; externally peer reviewed. Data availability statement No data are available.

Open access This is an open access article distributed in accordance with the Creative Commons Attribution Non Commercial (CC BY-NC 4.0) license, which permits others to distribute, remix, adapt, build upon this work non-commercially, and license their derivative works on different terms, provided the original work is properly cited, appropriate credit is given, any changes made indicated, and the use is non-commercial. See: http://creativecommons.org/licenses/by-nc/4.0/.

\section{ORCID iD}

Alexander P Wolkow http://orcid.org/0000-0001-7845-3104

\section{REFERENCES}

1 Vila B. Impact of long work hours on police officers and the communities they serve. Am J Ind Med 2006;49:972-80.

2 Fekedulegn D, Burchfiel CM, Charles LE, et al. Shift work and sleep quality among urban police officers. Journal of Occupational and Environmental Medicine 2016;58:e66-71.

3 Rajaratnam SMW, Barger LK, Lockley SW, et al. Sleep disorders, health, and safety in police officers. JAMA 2011;306:2567-78.

4 Maslach CM, Jackson SE, Leiter MP. Maslach burnout inventory: manual. 3rd edn. Palo Alto, CA: Consulting Psychologists Press, 1996.

5 McGreedy K. Selection practices and the police role. Police Chief 1974;41:41-3.

6 Crowe RP, Bower JK, Cash RE, et al. Association of burnout with Workforce-Reducing factors among EMS professionals. Prehosp Emerg Care 2018;22:229-36.
7 Summerfield D. Metropolitan police blues: protracted sickness absence, ill health retirement, and the occupational psychiatrist. BMJ 2011;342:d2127.

8 Amendola K, Weisburd D, Hamilton E, et al. The impact of shift length in policing on performance, health, quality of life, sleep, fatigue, and Extra-Duty employment: National Institute of justice, office of justice programs, us department of justice 2011

9 Barger LK, Lockley SW, Rajaratnam SMW, et al. Neurobehavioral, health, and safety consequences associated with shift work in safety-sensitive professions. Curr Neurol Neurosci Rep 2009;9:155-64.

10 Cheng W-J, Cheng Y. Night shift and rotating shift in association with sleep problems, burnout and minor mental disorder in male and female employees. Occup Environ Med 2017;74:483-8.

11 Yoo H, Franke WD. Sleep habits, mental health, and the metabolic syndrome in law enforcement officers. J Occup Environ Med 2013;55:99-103.

12 Embriaco N, Azoulay E, Barrau K, et al. High level of burnout in intensivists: prevalence and associated factors. Am J Respir Crit Care Med 2007;175:686-92.

13 Dall'Ora C, Griffiths P, Ball J, et al. Association of $12 \mathrm{~h}$ shifts and nurses' job satisfaction, burnout and intention to leave: findings from a cross-sectional study of 12 European countries. BMJ Open 2015;5:e008331.

14 Stimpfel AW, Sloane DM, Aiken LH. The longer the shifts for hospital nurses, the higher the levels of burnout and patient dissatisfaction. Health Aff 2012;31:2501-9.

15 Boudreaux E, Mandry C, Brantley PJ. Emergency medical technician schedule modification: impact and implications during short- and long-term follow-up. Acad Emerg Med 1998;5:128-33.

16 Fahrenkopf AM, Sectish TC, Barger LK, et al. Rates of medication errors among depressed and burnt out residents: prospective cohort study. BMJ 2008;336:488-91.

17 Burke RJ, Mikkelsen A. Burnout among Norwegian police officers: potential antecedents and consequences. Int J Stress Manag 2006;13:64-83.

18 Martinussen M, Richardsen AM, Burke RJ. Job demands, job resources, and burnout among police officers. J Crim Justice 2007;35:239-49.

19 Metlaine A, Sauvet F, Gomez-Merino D, et al. Association between insomnia symptoms, job strain and burnout syndrome: a cross-sectional survey of 1300 financial workers. BMJ Open 2017;7:e012816.

20 Lockley SW, Cronin JW, Evans EE, et al. Effect of reducing interns' Weekly work hours on sleep and attentional failures. N Engl J Med 2004;351:1829-37.

21 Alterman T, Luckhaupt SE, Dahlhamer JM, et al. Prevalence rates of work organization characteristics among workers in the U.S.: data from the 2010 National health interview survey. Am J Ind Med 2013;56:647-59.

22 Saha I, Mitra S. Does emotional intelligence upon interaction with perceived stress, moderate burnout among resident doctors? A study from West Bengal, India. Int J Community Med Public Health 2018;5:4382-7.

23 Johns MW. Sensitivity and specificity of the multiple sleep latency test (MSLT), the maintenance of wakefulness test and the Epworth Sleepiness scale: failure of the MSLT as a gold standard. J Sleep Res 2000;9:5-11

24 De la Fuente Solana El, Aguayo Extremera R, Vargas Pecino C, et al. Prevalence and risk factors of burnout syndrome among Spanish police officers. Psicothema 2013;25:488-93.

25 Kou K-Y, H-H W. Assessing emotional exhaustion of police officers in Taiwan by multivariate analysis of variance. TEM Journal 2016:5:347-52.

26 Wolf MR, Rosenstock JB. Inadequate sleep and exercise associated with burnout and depression among medical students. Acad Psychiatry 2017;41:174-9.

27 Houdmont J, Randall R. Working hours and common mental disorders in English police officers. Occup Med 2016;66:713-8.

28 Ranganathan P, Pramesh CS, Aggarwal R. Common pitfalls in statistical analysis: logistic regression. Perspect Clin Res 2017:8:148-51.

29 Bureau of Labor Statistics. Current population survey (CPS): annua averages-household data 2007.

30 Flegal KM, Kruszon-Moran D, Carroll MD, et al. Trends in obesity among adults in the United States, 2005 to 2014. JAMA 2016;315:2284-91.

31 Shanafelt TD, Boone S, Tan L, et al. Burnout and satisfaction with work-life balance among US physicians relative to the general US population. Arch Intern Med 2012;172:1377-85. 
32 Beckers DGJ, van der Linden D, Smulders PGW, et al. Voluntary or involuntary? control over overtime and rewards for overtime in relation to fatigue and work satisfaction. Work \& Stress 2008;22:33-50.

33 Wisetborisut A, Angkurawaranon C, Jiraporncharoen W, et al. Shift work and burnout among health care workers. Occup Med 2014;64:279-86.

34 Bedrosian TA, Nelson RJ. Timing of light exposure affects mood and brain circuits. Transl Psychiatry 2017;7:e1017.

35 Grunfeld E, Whelan TJ, Zitzelsberger L, et al. Cancer care workers in Ontario: prevalence of burnout, job stress and job satisfaction. CMAJ 2000;163:166-9.

36 Schaufeli W, Enzmann D. The burnout companion to study and practice: a critical analysis. Philadelphia, PA: CRC Press, Taylor \& Francis Group, 1998.

$37 \mathrm{Ma}$ CC, Andrew ME, Fekedulegn D, et al. Shift work and occupational stress in police officers. Saf Health Work 2015;6:25-9.

38 Arendt J. Shift work: coping with the biological clock. Occup Med 2010;60:10-20.
39 Burnout JM. Stress and health of employees on non-standard work schedules: a study of Canadian workers. Stress Health 2004;20:113-9.

40 Lemola S, Ledermann T, Friedman EM. Variability of sleep duration is related to subjective sleep quality and subjective well-being: an actigraphy study. PLoS One 2013;8:e71292.

41 Sallinen M, Härmä M, Mutanen P, et al. Sleep-Wake rhythm in an irregular shift system. J Sleep Res 2003;12:103-12.

42 Shamali M, Shahriari M, Babaii A, et al. Comparative study of job burnout among critical care nurses with fixed and rotating shift schedules. Nurs Midwifery Stud 2015;4:e27766.

43 Shahriari M, Shamali M, Yazdannik A. The relationship between fixed and rotating shifts with job burnout in nurses working in critical care areas. Iran J Nurs Midwifery Res 2014;19:360-5.

44 Folkard S. Do permanent night workers show circadian adjustment? A review based on the endogenous melatonin rhythm. Chronobiol Int 2008;25:215-24. 